\title{
Variability and Uncertainty on Rock Mass Strength Via a Synthetic Rock Mass Approach
}

\author{
C. Lambert CSIRO Exploration and Mining, Australia
}

\begin{abstract}
By combining the benefits of the particle flow code PFC3D to represent the rock and the benefits of a geostatistical tool to generate a full three-dimensional (3D) discrete fracture network (DFN) of the domain, it is possible to create, using typical field data, a synthetic rock mass (SRM) that is representative of the geotechnical domain. The SRM is then submitted to a series of numerical tests (triaxial tests, UCS tests) using PFC3D to assess the constitutive behaviour of the rock mass. The model exhibits a wide range of typical behaviours of a real rock mass, such as anisotropy and a scale effect.
\end{abstract}

To better understand the influence of the structural pattern of a rock mass on its strength, an extensive series of simulations has been carried out varying some of the key parameters of the DFN (joint persistence, joint spatial density or joint friction angle). The results of the simulations are analysed and discussed. An attempt to characterise the rock mass strength variability is proposed.

\section{Introduction}

The SRM approach is a methodology that has been developed by Pierce et al. (2007) within PFC3D (Itasca, 2006) in order to predict the mechanical behaviour of jointed rock masses. The methodology involves the construction and testing of a 3D SRM sample. SRM samples represent the rock mass as an assembly of bonded particles where a joint network is introduced as a series of disc-shaped fractures. The methodology describes the joints behaviour using a smooth joint model. This approach brings together the benefits of two methods, the bonded particle model proposed by Potyondy and Cundall (2004) to simulate intact rock and DFN simulations to construct a 3D joint pattern. Many different loading paths can then be applied to SRM samples of different shapes to predict the behaviour of the rock mass. Using only data obtained from standard rock mass characterisation methods, the methodology has proven its ability to reproduce a wide range of typical behaviours of a rock mass. Amongst the most interesting features are the anisotropy and the scale dependency of the rock mass strengths and the possibility to quantify the rock mass brittleness in a caving environment. For a detailed description of the methodology one can refer to Pierce et al. (2007) or Mas Ivars et al. (2008).

In the present work, the SRM methodology has been used to study the rock mass strength in a complex geological environment. Whether dealing with a mining or a civil engineering context, complexity often goes together with variability in the measured engineering properties and uncertainties. Taking advantage of the benefits of the SRM approach, a method is proposed to quantify the impact on the rock mass strength generated by the uncertainty and variability of some of the geotechnical data. The SRM samples have been developed on the basis of data coming from the BHP Billiton Nickel West project in Western Australia. A parametric study is conducted by varying some of the input parameters.

\section{The SRM approach}

Predicting a rock mass behaviour with the SRM approach is a three steps process. First a particle assembly is created in PFC3D, representing the intact rock of the considered rock mass. Then a fracture network representative of the joint fabric is generated and imported into the particle assembly to create a large SRM sample. The created sample is finally submitted to a variety of different loadings to predict the rock mass behaviour. 


\subsection{Intact rock representation}

Intact rock is represented as an assembly of bonded spheres as described by Potyondy and Cundall (2004). The bonded particle model (BPM) requires microproperties as input parameters that are calibrated against laboratory macroproperties (elasticity and strength). In the geotechnical unit considered for this study, many different rock types can be found but only three of them have a volume fraction higher than three per cent (mafic intrusive, mafic volcanic and basalt). Only those three rock types have been considered in this study. Their mechanical properties, which have been evaluated through standard laboratory experimental tests, are listed in Table 1. Using the procedures outlined by Potyondy and Cundall (2004) for creation and testing a $\mathrm{BPM}$, for each rock type, a series of numerical uniaxial compression tests were conducted on $2 \times 4 \mathrm{~m}$ cylindrical PFC3D samples to match the target properties. The UCS and Young's modulus obtained for the PFC3D material are listed in Table 1 and the microproperties used for each rock type are listed in Table 2. Since it is not always possible to subdivide a domain on the rock type basis, a fourth PFC3D material has been created representing the intact rock as a mixture of the different lithologies. The different microproperties have been randomly distributed in the particle assembly on the basis of their relative volume fraction observed in the field (mafic intrusive 25\%, mafic volcanic 57\% and basalt 18\%). A series of unconfined compression tests have been performed on the obtained mixture to evaluate its UCS and Young's modulus. The obtained properties are listed in Table 1.

Table 1 Measured and simulated intact rock properties

\begin{tabular}{lccccccc}
\hline & \multicolumn{2}{c}{ Mafic Intrusive } & \multicolumn{2}{c}{ Mafic Volcanic } & \multicolumn{2}{c}{ Basalt } & Mixture \\
& Lab & PFC3D & Lab & PFC3D & Lab & PFC3D & PFC3D \\
\hline UCS [MPa] & 113.7 & 107.9 & 74.3 & 70 & 170 & 166.3 & 112.6 \\
Young's modulus E [GPa] & 96.6 & 98.0 & 28.8 & 29.5 & 30 & 30 & 70.9 \\
\hline
\end{tabular}

Table 2 Microproperties used in SRM samples

\begin{tabular}{lccc}
\hline & Mafic Intrusive & Mafic Volcanic & Basalt \\
\hline Particle properties & & & \\
Ball density $\left[\mathrm{kg} / \mathrm{m}^{3}\right]$ & 4109.0 & 4109.0 & 4109.0 \\
Ball-ball contact modulus [GPa] & 184.0 & 51.2 & 52.0 \\
Ball stiffness ratio kn/ks & 4.0 & 3.5 & 3.5 \\
Ball friction coefficient & 0.7 & 0.7 & 0.7 \\
Parallel bond properties & & & \\
Parallel-bond radius multiplier & 1.0 & 1.0 & 1.0 \\
Parallel-bond modulus [GPa] & 184.0 & 51.2 & 52.0 \\
Parallel-bond stiffness ratio & 4.0 & 3.5 & 3.5 \\
Mean parallel-bond normal strength [MPa] & 151.6 & 99.1 & 210.0 \\
Standard deviation of parallel-bond normal strength [MPa] & 20.0 & 20.0 & 40.0 \\
Mean parallel-bond shear strength [MPa] & 151.6 & 99.1 & 210.0 \\
Standard deviation of parallel-bond shear strength [MPa] & 20.0 & 20.0 & 40.0 \\
\hline
\end{tabular}

Using the calibrated microproperties, a $24 \mathrm{~m}$ cube sample (i.e. $24 \times 24 \times 24 \mathrm{~m}$ ) of bonded particles was constructed for each of the three rock types and for the mixture. 


\subsection{DFN realisation and joint representation}

The second step of the SRM construction process is the introduction of the fracture pattern. Using the DFN modelling technique it is possible to represent the different structures of a rock slope from in situ measured data. The fracture network can then be imported into the SRM for an explicit representation of the joints of the rock mass.

For this study, a DFN of the domain has been developed using JK JointStats, a discontinuity data management system developed at the University of Queensland by the Julius Kruttschnitt Mineral Research Centre (JKMRC) (2000). All the structural data coming from borehole logging or scanline mapping can be imported into the system where statistical analysis are performed using maximum likelihood methods (Lyman, 2003). Estimates of joint set orientation, persistence and spatial density are provided, including confidence interval calculations. The DFN realisations that are generated are statistically representative of the domain, providing that the volume of study is large enough. Each joint set of the output DFN is in complete agreement with the statistical description of the input data. The joint orientation distribution that has been used to create our DFN (in a $100 \times 100 \times 100 \mathrm{~m}$ cube volume) is shown on Figure 1. The persistence and spacing information for each joint set is listed in Table 3. Subvertical jointing is clearly predominant, with a preferred orientation striking roughly north-south. However a strong subhorizontal joint set can be identified.
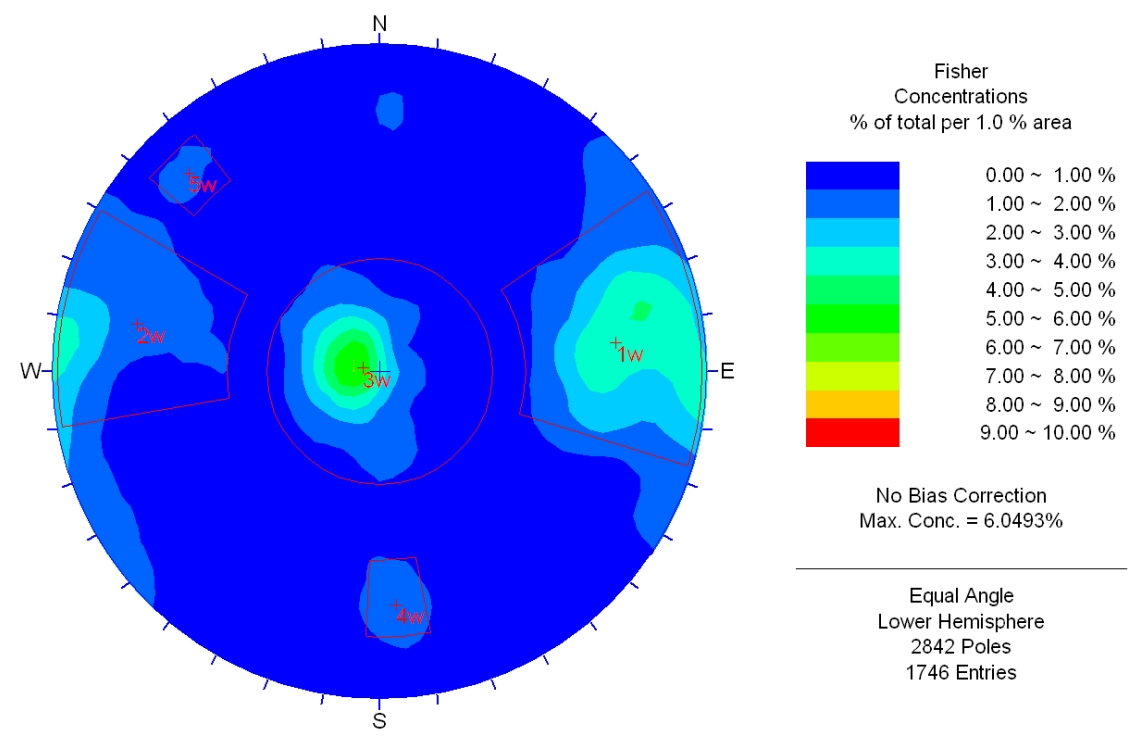

Figure 1 Stereonet representation used to construct the DFN

Table 3 Joint set data

\begin{tabular}{ccccc}
\hline Joint Set & Avg. Dip $\left(^{\circ}\right)$ & Avg. DD $\left(^{\circ}\right)$ & Avg. Spacing $(\mathrm{m})$ & Avg. size $(\mathrm{m})$ \\
\hline 1 & 75.7 & 262 & 2.1 & 7.5 \\
2 & 76.8 & 100.5 & 6.6 & 13.7 \\
3 & 5.5 & 146.8 & 2.8 & 15.0 \\
4 & 70.8 & 358.5 & 13.7 & 4.4 \\
5 & 79.9 & 131 & 30.0 & 15.0 \\
\hline
\end{tabular}

Examples of two-dimensional (2D) sections of the DFN realisation are shown in Figure 2. The current DFN realisation contains 35,011 joints within the $100 \mathrm{~m}$ cube volume from which a $24 \mathrm{~m}$ cube (i.e. $24 \mathrm{x} 24 \mathrm{x}$ $24 \mathrm{~m}$ ) can be extracted and imported within the SRM samples. 
The joints have been represented using the smooth joint model proposed by Pierce et al. (2007). This new contact scheme allows the elimination of the roughness or bumpiness induced by the particles when simulating a joint by simply debonding the contact along a plane. Instead, a sliding plane is introduced through a dip and dip direction for each contact between particles that lie upon opposite sides of the specified plane. This plane defines the general direction of sliding of the particles which are set free to overlap eachother. Dilation has also been added to the smooth joint model formulation, which requires the definition of five parameters normal and shear stiffness, friction angle, cohesion and dilation angle. One single set of parameters has been used to model the five joints sets. The values used in this study can be found in Table 4 .
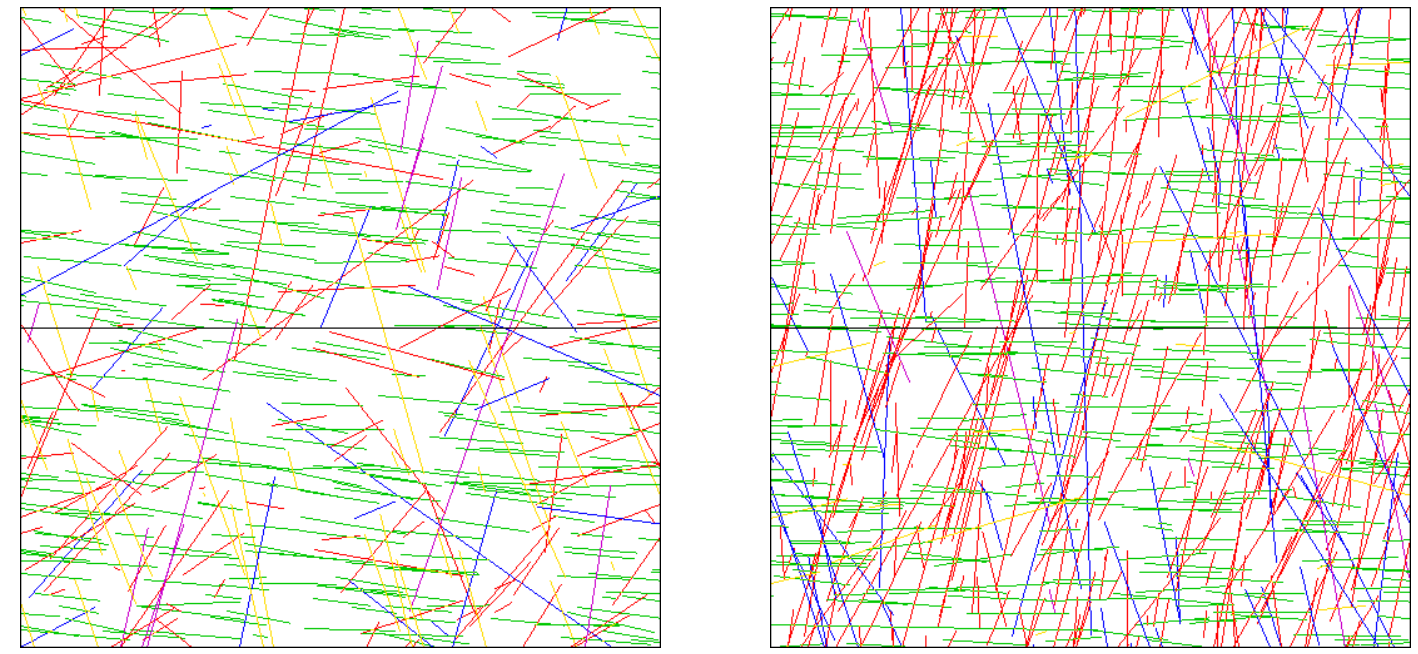

Figure 2 2D vertical sections $(100 \times 100 \mathrm{~m})$ of the DFN realisation. N-S section on the left and E-W section on the right

Table 4 Smooth joint model properties

\begin{tabular}{lc}
\hline Friction angle $\left[^{\circ}\right]$ & 30 \\
Cohesion $[\mathrm{MPa}]$ & 0 \\
Dilation angle $\left[{ }^{\circ}\right]$ & 0 \\
Normal stiffness $[\mathrm{Pa} / \mathrm{m}]$ & $150 \mathrm{e} 9$ \\
Shear stiffness $[\mathrm{Pa} / \mathrm{m}]$ & $20 \mathrm{e} 9$ \\
\hline
\end{tabular}

\subsection{Unconfined compression test on SRM samples}

A $24 \mathrm{~m}$ cube has been extracted from the previous DFN and imported into the four particles assembly constructed previously. Four SRM samples are thus obtained having exactly the same joint pattern and representing the three significant lithologies of the domain and a mixture of those three lithologies. A numerical unconfined compression test has been performed on each of the SRM. The loading has been applied in a north-south direction, following the procedure detailed by Pierce et al. (2007). Each test took approximately 30 hours to complete on a single processor $3 \mathrm{GHz}$ PC. The obtained stress-strain curves for the different tests are represented on Figure 3.

As expected, the UCS of the SRM appears to be highly dependant on the rock type and more specifically on its strength. Because the domain of the present study is composed of rock types exhibiting a large variation in their strength, the strength of the SRM reflects this variation and goes from $41.5 \mathrm{MPa}$, for rock mass made of mafic volcanic, to $86 \mathrm{MPa}$ for a rock mass made of basalt, i.e. more than $100 \%$ relative difference. In the field, the rock mass would, of course exhibit a behaviour standing somewhere between those two extreme boundaries. Strictly, characterising the domain as a homogeneous rock type is not satisfactory and each lithology should be represented in any stability analysis as an independent geotechnical domain. However, in some cases of complex geology, subdividing the domains can require an exhaustive rock type mapping and/ or generates an unreasonable number of geotechnical units. An alternative approach would be to develop an 
SRM model that can accommodate the existence of different rock types. Creating a randomly distributed mixture of the rock types is the most straightforward way to overcome the problem. The result of a compression test of the corresponding SRM sample can be seen on Figure 3 and compared the homogeneous SRM samples. A completely random distribution of the rock types does not reflect reality in field where the different lithologies are more continuous. Introducing a length in the spatial variation of the rock types would certainly better reflect reality. The main consequence of the fully random distribution adopted in this study would be to slightly overestimate the strength of the rock mass as showed by Jefferies et al. (2008).

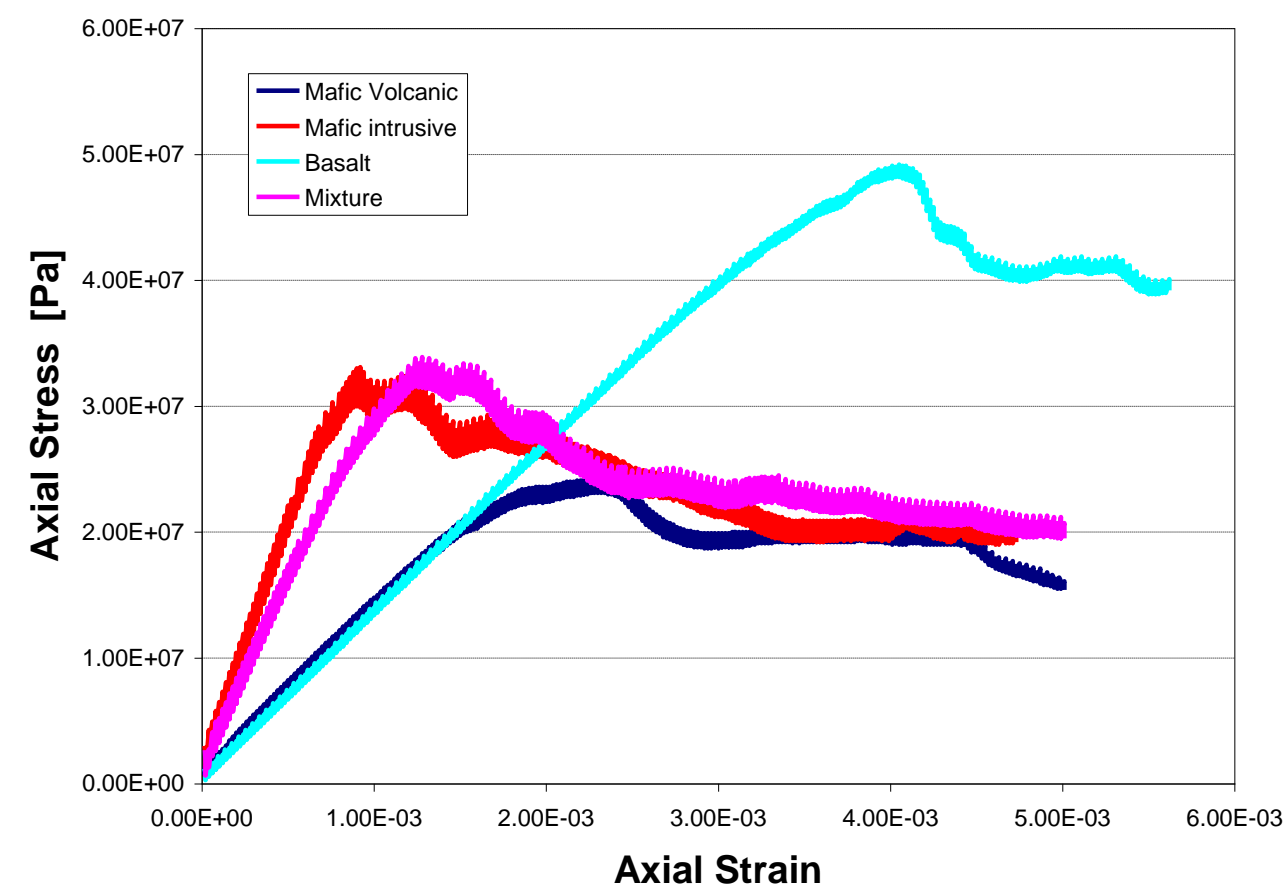

Figure 3 Stress-strain curves of uniaxial compression tests for three different rock types and a mixture of the rock types

\section{Rock mass strength characterisation}

From now and for the rest of this study, the rock mass has been represented as a mixture of its different components (i.e. the mixture model) and one has to keep in mind the limitations of the approach as discussed above.

\subsection{Strength characterisation}

Because the DFN has been statistically generated, it is not homogenous in space. Variations in dip, dip direction, joint spacing and joint size occur for each joint set within the volume of interest. Each DFN generated in that way is unique but statistically identical if the volume of interest is large enough. In this study only $24 \mathrm{~m}$ cubic samples are tested. On such volumes, the number of joints in some of the joint sets will not be large enough to be representative and the differences in the as-built sub-DFN can result into differences in the SRM strength. For a better estimate of the rock mass strength, three $24 \mathrm{~m}$ cube samples have been tested extracting their fracture pattern from three different locations of the DFN. The strength of the rock mass is then obtained averaging the results from the different SRM samples.

The strength of a rock mass cannot be defined only through its UCS. The SRM samples have been submitted to a series of numerical triaxial compression tests at various confining pressures $(0,2$ and $10 \mathrm{MPa})$ from which a partial strength envelope is obtained. A total of three triaxial tests series have been performed on each of the samples changing the loading direction (E-W, N-S and vertical). From the compression strengths $\sigma_{1}{ }^{\mathrm{EW}}, \sigma_{1}{ }^{\mathrm{NS}}$ and $\sigma_{1}{ }^{\text {Vert }}$ (designating respectively the strength in an east-west loading direction, north-south and vertical), strength envelopes were developed for each loading direction and are shown in Figure 4. A clear anisotropy is enhanced in the horizontal plane between N-S and E-W directions and with the vertical 
direction. A close comparison between the two horizontal directions shows a slight reduction in strength anisotropy with confining pressure $\sigma_{3}$. The ratio between peak stresses $\sigma_{1}{ }^{\mathrm{EW}}$ and $\sigma_{1}{ }^{\mathrm{NS}}$ decreases from 2.7 without confinement to 2.0 at $10 \mathrm{MPa}$. A similar reduction in the anisotropy of rock has been observed on different rocks by Ramamurthy (1993). A rapid deterioration of the strength anisotropy can be seen for a ratio of uniaxial compression strength $\sigma_{\mathrm{c}}$ over confining pressure $\sigma_{3}$ lower than five and the anisotropy is reduced to less than $10 \%$ for most of the rocks for $\sigma_{d} / \sigma_{3}=1$. Applied to this study, the deterioration of the anisotropy can be expected to increase with $\sigma_{3}$ until being significant for confining pressure greater than $20 \mathrm{MPa}$.

Interestingly, comparison of $\sigma_{1}{ }^{\mathrm{NS}}$ and the peak stress in the vertical direction $\sigma_{1}{ }^{\text {Vert }}$ revealed an increase in the strength anisotropy with $\sigma_{c}$, in apparent contradiction with the expected tendency. This suggests that a different phenomenon is involved. A feature of the fracture network of the rock mass is that four of the five joint sets are sub vertical. The blocks of the rock mass thus exhibit an elongated shape in the vertical direction. Yet particle shape has been proven to strongly influence the behaviour of granular material. Nouguier et al. (2003) studied the behaviour of elongated polygonal grains for different loading directions (parallel to grain orientation and orthogonal to grain orientation). A load applied in the grain direction resulted in particle rotations gradually reversing the anisotropy. By making an analogy between our rock mass and an elongated particles granular material, similar behaviour can be expected when loading in the vertical direction and applying a confining pressure, which will prevent the blocks from rotating and thus preserve the initial anisotropy. The increase of the anisotropy with $\sigma_{\mathrm{c}}$ should however be limited at high confining pressure with the onset of the ductile response as proposed by Ramamurthy (1993).

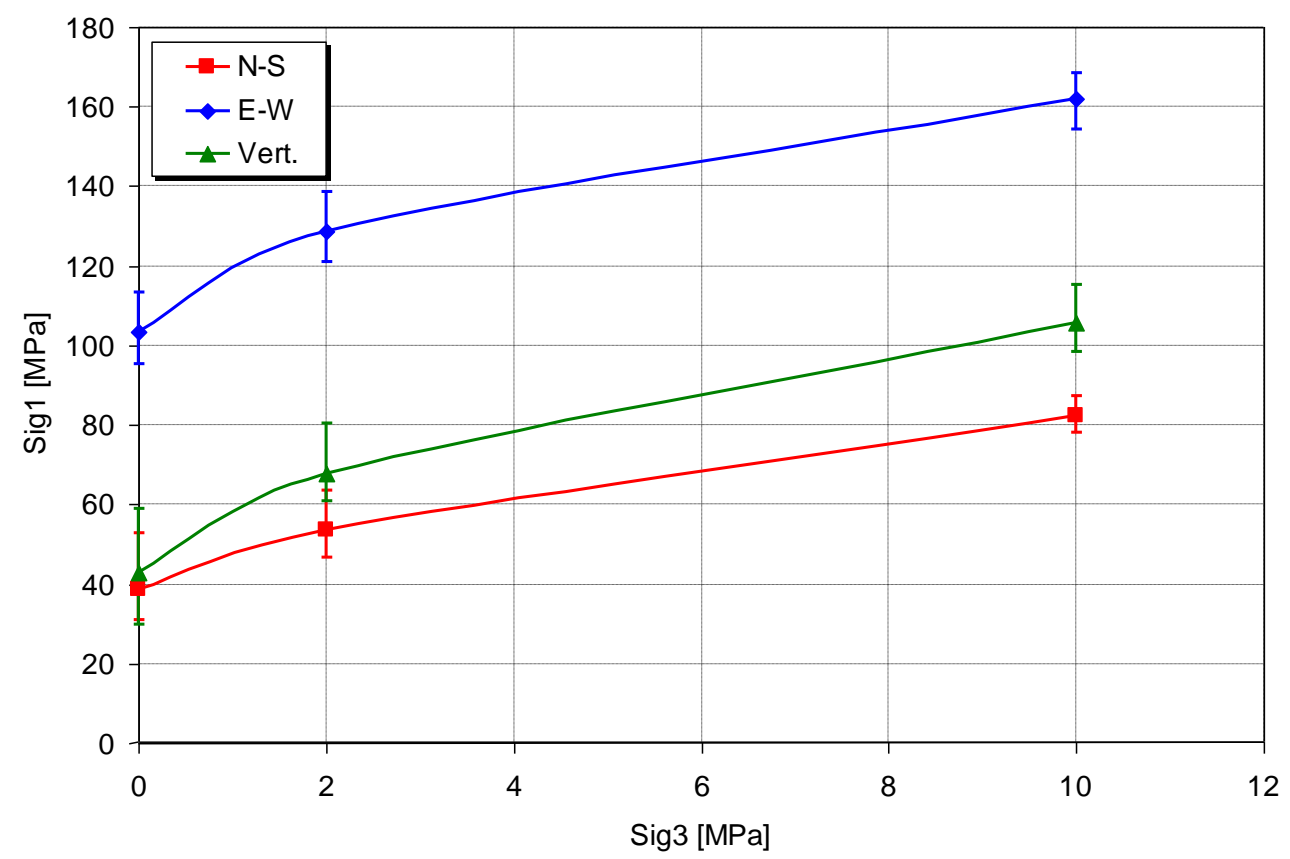

Figure 4 Strength envelopes of the SRM in three different directions (N-S squares, E-W diamonds and vertical triangles)

\section{Strength variability of the rock mass}

Whether these come from the intrinsic variability of intact rock properties or from the joint spatial distribution, rock masses are variable in their engineering properties. In conventional geotechnical practice, a rock slope is divided into geotechnical units which are assigned constant properties. This idealisation of reality does not reflect the variability occurring within the slope. In recent years, different studies explicitly introduced a spatial variation of intact rock properties in order to analyse its impact on rock slope stability (Hsu and Nelson, 2006; Jefferies et al., 2008). The strength variability was introduced as a distribution of intact rock properties or GSI values that would reflect the variability of experimental and field observations. However, different components of a rock mass can contribute to this variability, the intact rock, the joint 
strength or the joint size and spacing. The SRM approach has been used to better understand the impact on the rock mass strength that a variation of those parameters can have, i.e. impact of intact rock strength, joint strength and joint size. Different SRM samples have constructed as presented in Section 0, each time varying only one parameter. The created samples have then been submitted to an unconfined compression test in a north-south loading direction and the variations of their strength have been analysed.

\subsection{Variability from intact rock strength}

The variability of intact rock strength has been analysed using the UCS tests presented in Section 0 (Figure 3). In those tests, four intact rock types were tested (mafic intrusive, mafic volcanic, basalt and a mixture of the previous three rock types). The same DFN has been introduced in the different samples so that the contribution of the fracture pattern to the rock mass behaviour can be expected to be the same from one simulation to another. Hence, the variations observed are considered as an intact rock effect only. The variation of the strength of the SRM $\sigma_{\text {crm }}$ with intact rock strength $\sigma_{\text {ci }}$ can be seen Figure 5.

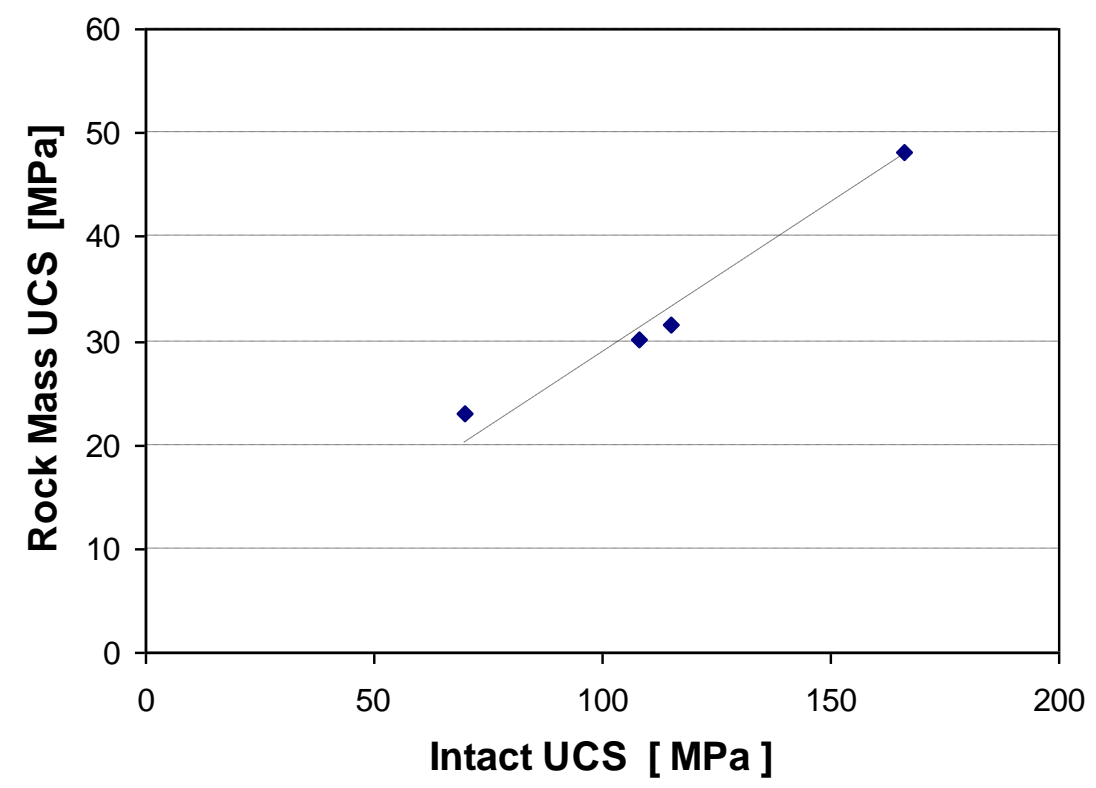

Figure 5 SRM uniaxial compression strength as a function of intact rock UCS

The results show that an apparent linear relation between intact UCS $\sigma_{\mathrm{ci}}$ and rock mass UCS $\sigma_{\mathrm{crm}}$ can be drawn. We know from probability theory that if $\mathrm{X}_{1}$ is a normal random variable and $\mathrm{A}$ and $\mathrm{B}$ are two real numbers, then $X_{2}$ defined as $A * X+B$ follows a random normal distribution. The mean value $\mu_{2}$ and standard deviation $\sigma_{2}$ of the latter random variable directly derive from the mean value $\mu_{1}$ and standard deviation $\sigma_{1}$ of the initial variable in the following way:

$$
\begin{aligned}
& \mu_{2}=\mathrm{A} \times \mu_{1}+\mathrm{B} \\
& \sigma_{2}=\mathrm{A} \times \sigma_{1}
\end{aligned}
$$

The mean strength of the mixture has been evaluated to $113 \mathrm{MPa}$. By assuming a standard deviation of $30 \mathrm{MPa}$ and using the equation of the trendline in Figure 5, the rock mass strength is then given by Equation (2):

$$
\sigma_{\mathrm{crm}}=31.6 \mathrm{MPa} \pm 8.4
$$

The mean value and standard deviation for the rock mass strength fully define the probability distribution of $\sigma_{\mathrm{crm}}$. Confidence intervals are then derived from the probability distribution. The intervals are represented in Figure 6 where each histogram bar represents a confidence level, its position the value of $\sigma_{\mathrm{crm}}$ at that confidence level and its eights the probability of $\sigma_{\mathrm{crm}}$. This plot can then be used to assess the uncertainty on our rock mass strength. We are $90 \%$ sure that the rock mass strength lies between 17.8 and $45.5 \mathrm{MPa}$, 
whereas we can be only $20 \%$ sure that its strength is between 29.5 and $33.8 \mathrm{MPa}$. In other words, the most probable value for $\sigma_{\mathrm{crm}}$ is $31.6 \mathrm{MPa}$ but there is a $40 \%$ probability for the actual strength of the rock mass to be lower than $29.5 \mathrm{MPa}$ (and $40 \%$ chance to be higher than $33.8 \mathrm{MPa}$ ). The uncertainty information can then used for a probability of failure estimate or included into a reliability analysis.

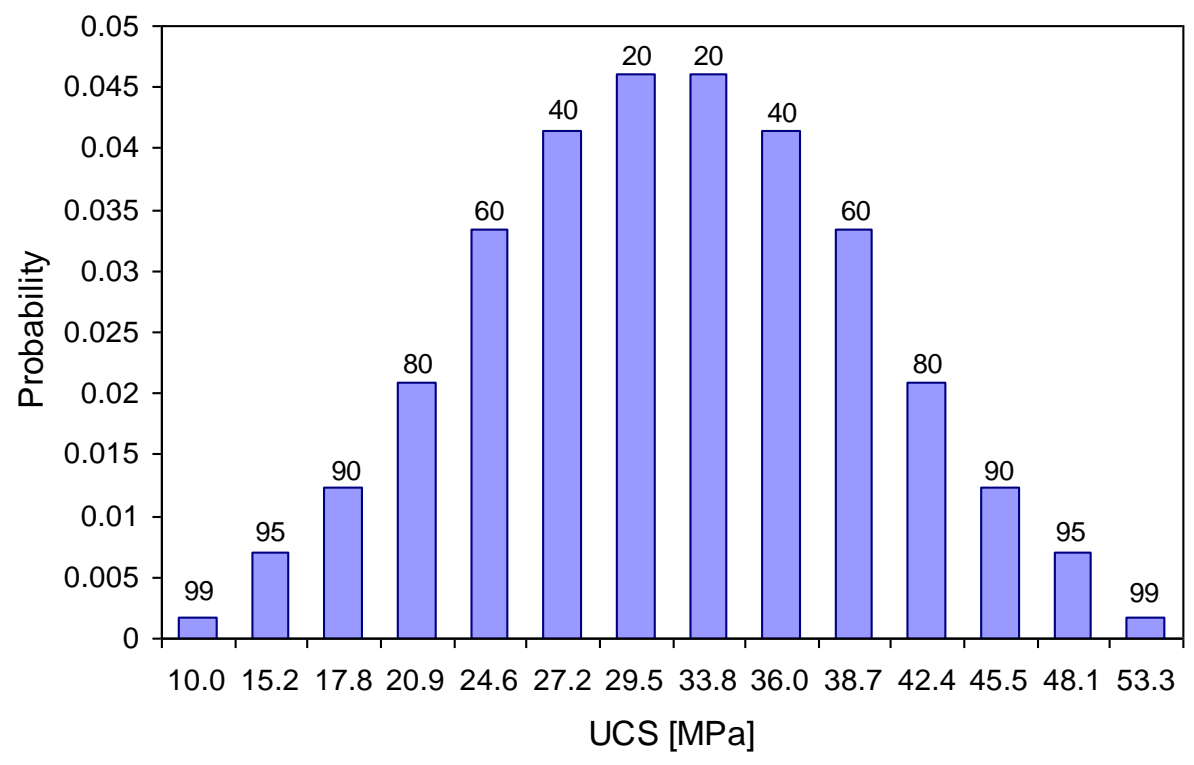

\section{Figure 6 Probability and confidence intervals on rock mass strength. Effect of the variability of intact rock strength $\sigma_{\mathrm{ci}}$}

\subsection{Variability from joint strength}

The effect on the rock mass strength of the uncertainty on the joint strength is presented here using a similar approach. Five SRM samples have been created varying the joint friction angle $\varphi\left(0^{\circ}, 10^{\circ}, 20^{\circ}, 25^{\circ}\right.$ and $\left.30^{\circ}\right)$ and each sample has been submitted to a UCS test. The evolution of $\sigma_{\mathrm{crm}}$ with the joint friction angle can be seen on Figure 7 showing a clear linear relation.

Hence a probability distribution of $\sigma_{\mathrm{crm}}$ can be obtained assuming a standard deviation of five degrees for the friction angle.

$$
\sigma_{\mathrm{crm}}=31.7 \mathrm{MPa} \pm 4
$$

The corresponding confidence limits are represented on Figure 7.

\subsection{Variability from joint set size}

In order to study the impact of the joint size uncertainty, seven SRM samples have been created using eight different joint patterns (the intact rock was represented as a mixture). The different patterns have been obtained multiplying the diameter of each joint of the initial pattern by a constant factor $(0.5,0.7,0.9,1.1$, $1.2,1.45$ and 1.5), the only difference between two SRM samples being the joint size. Each SRM has the same number of joints, each joint has exactly the same position and the same orientation. The results of the UCS tests are reported on Figure 8.

The relation appears to be bilinear in that case thus suggesting that the strength reduction is driven by two distinct phenomena. Figure 9 represent the fragmentation curve of the different samples before testing. Those curves inform on the size distribution of the continuous block within the sample. In a continuous block, the particles are linked together with a continuous chain of bonds. Those blocks can have partial cracks or embedded cracks but form one single piece of rock. Figure 9 shows that for a joint size lower than $110 \%$ of the initial reference size, more than $30 \%$ of the rock mass volume is continuous. For a multiplicative factor of 1.2 and above the rock mass appears clearly more and more discontinuous. In the first case, one can expect the loading to be mostly carried by this large piece of rock. The strength of the rock will thus be directly linked to the strength of that particular block and more specifically to the strength of the rock bridges 
in that block. Increasing the size of the joints reduces the size the rock bridges, thus weakening the SRM sample. In the second case, the SRM sample is more discontinuous. With the joint persistence increasing, the rock mass is evolving towards a completely blocky rock mass.
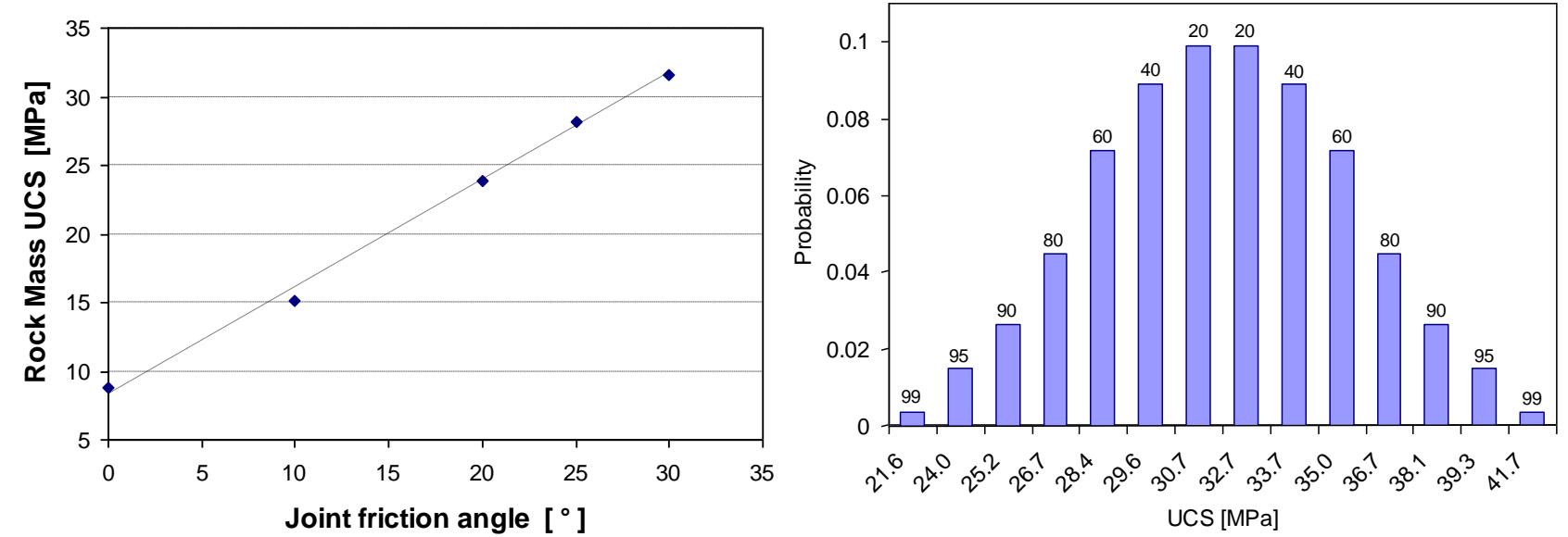

Figure 7 SRM uniaxial compression strength as a function of joint friction angle (left) and confidence intervals on rock mass strength as a result of joint friction angle uncertainty (right)

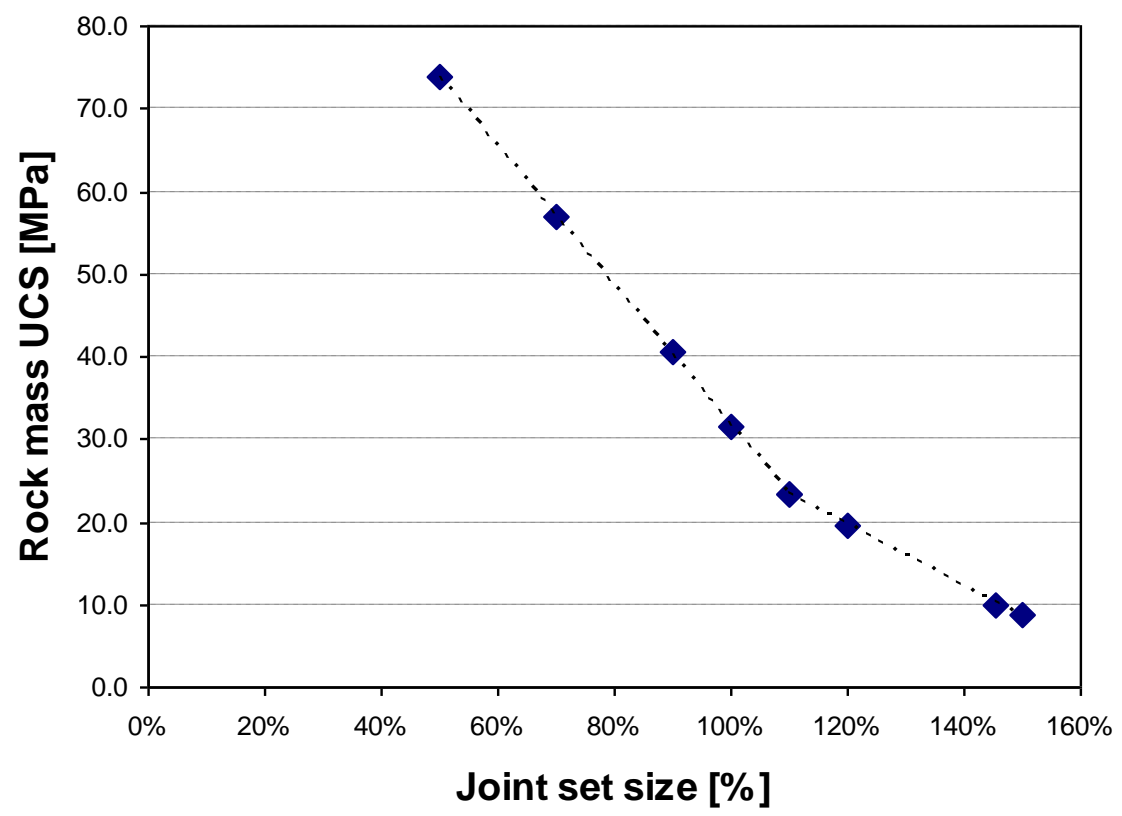

Figure 8 SRM uniaxial compression strength as a function of joint size multiplicative factor

Defining confidence intervals appears to be possible in the case of a continuous rock mass where joint persistence is lower that joint spacing. A linear relation between $\sigma_{\mathrm{crm}}$ and joint set size can be expected and the confidence intervals can be defined as described in section 0 . In the case of blocky rock mass, another linear relation can be expected leading to the definition of confidence intervals in the same way. By introducing a bilinear relation to describe the strength variability of our SRM samples, an estimate of confidence intervals can be obtained and is shown on Figure 10. However, no definitive conclusion can be drawn on what happens between those two extreme cases and further analysis is required to completely understand and quantify the impact that the variability of the joint set size has on the rock mass strength. 


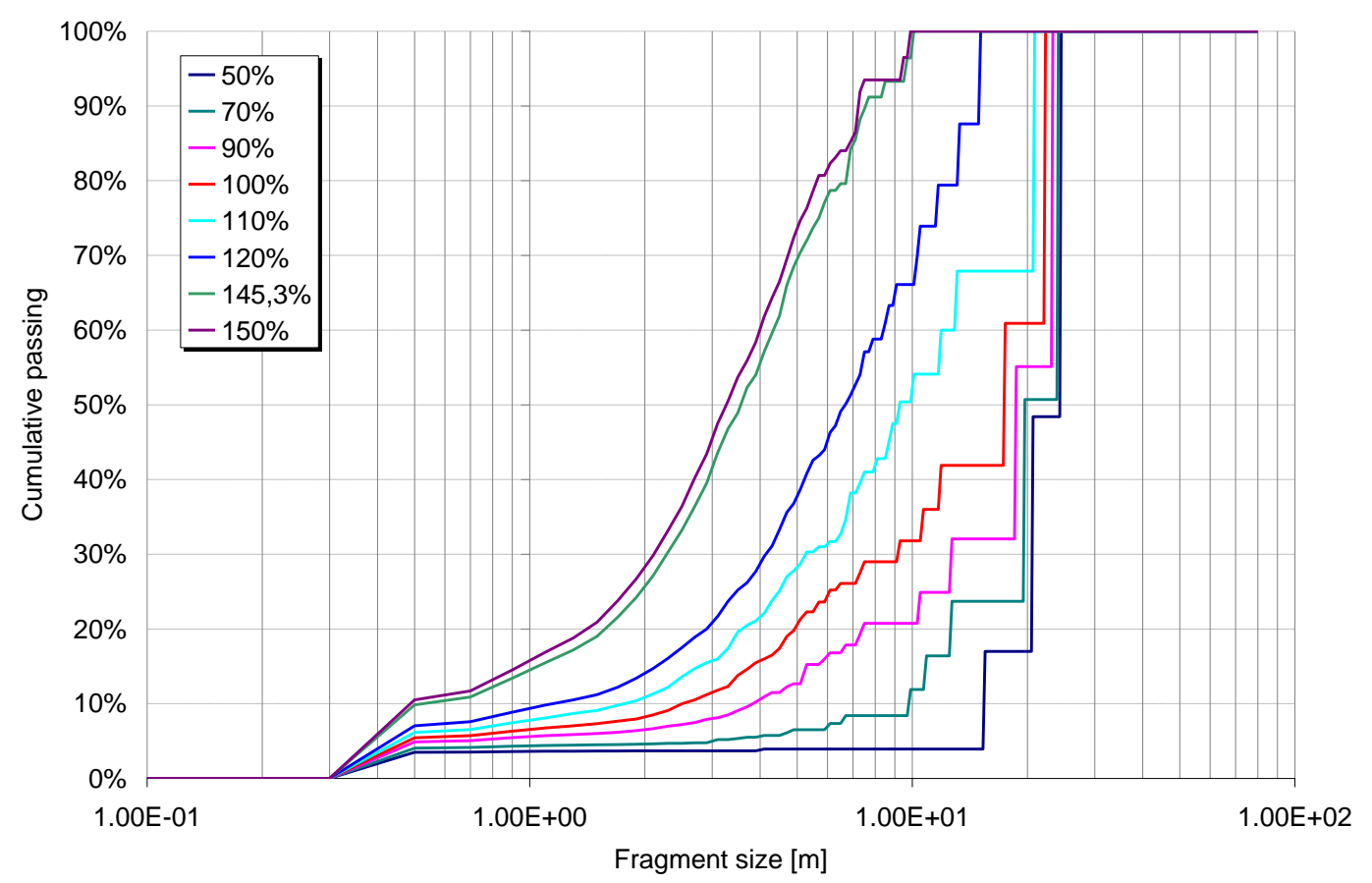

Figure 9 Fragmentation curves of the SRM samples with different joint size multiplicative factor

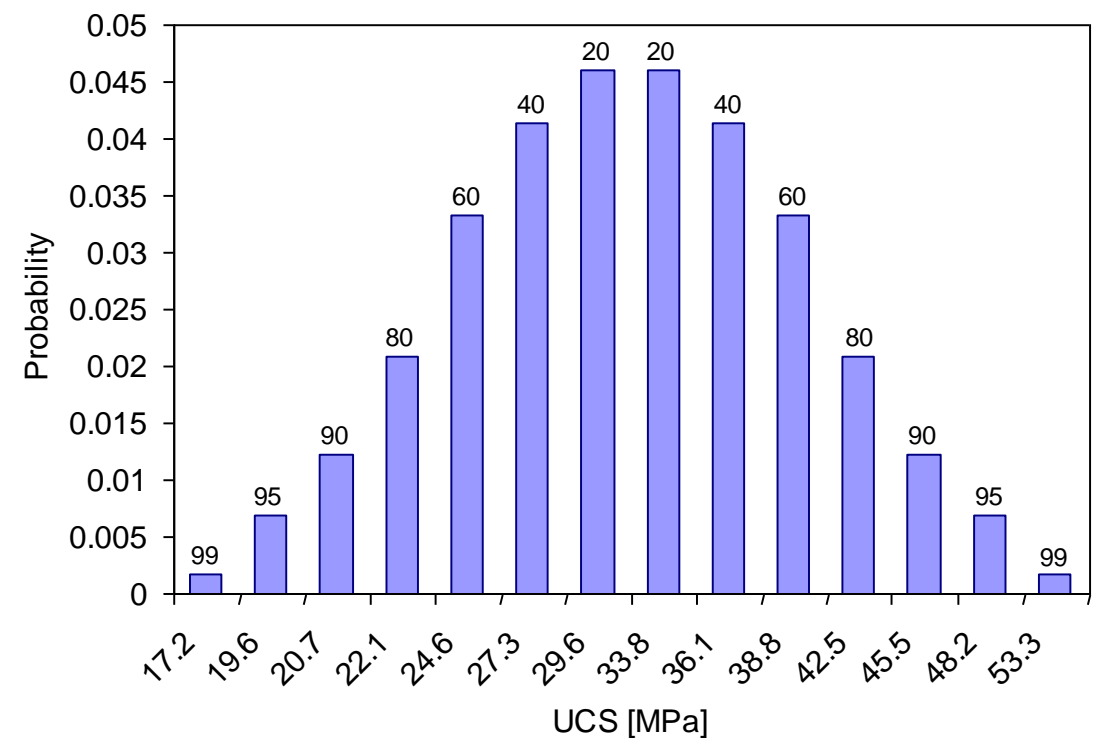

Figure 10 Confidence intervals on rock mass strength as a result of joint size uncertainty

\subsection{Effect of fracture frequency}

Modifying the joint size changes the fracture frequency of the rock mass. Another way of changing this fracture frequency is to modify the joint spacing. Different SRM samples have been created applying a multiplicative factor $(0.5,0.8,0.9,1.1,1.2$ and 1.5) to the spacing of each joint set. Joints have then been added or removed from each joint set of the initial DFN until matching the required spacing. The same numerical UCS test has been performed on these samples (N-S direction).

The effects of the various modifications on the fracture networks presented in section 0 and 0 have been compiled in terms of fracture frequency. The rock mass strengths are then plotted versus the fracture frequency of the corresponding joint pattern on Figure 11. The two data series, joint size modification with diamonds and joint spacing modification with triangles, shows a remarkable match. Increasing the size of the joints in your rock mass or reducing the spacing between the joints has the same effect on the strength 
reduction. The fracture frequency is the key factor to characterise the degree of fracturing of the rock mass and its effect on the strength.

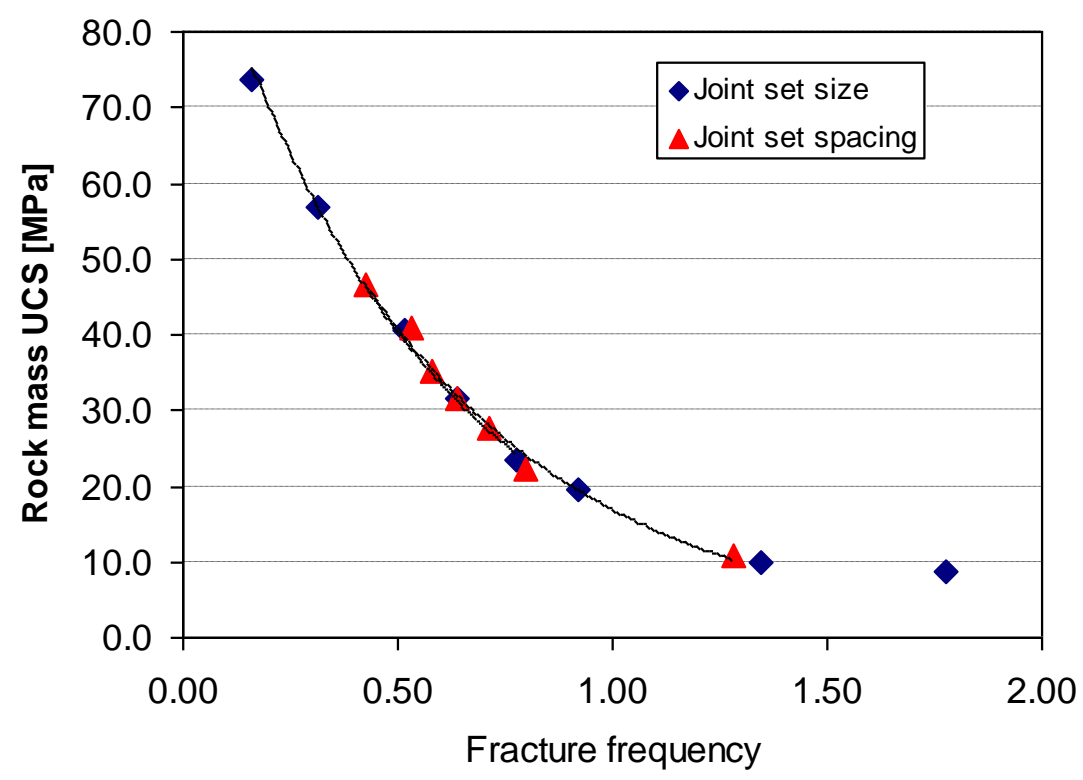

Figure 11 SRM uniaxial compression strength as a function of the fracture frequency in the loading direction

Ramamurthy (2001) proposed a formulation where the strength of a rock mass was expressed as function of a joint factor $\mathrm{J}_{\mathrm{f}}$. The joint factor is function of the joint frequency in the loading direction $\mathrm{J}_{\mathrm{n}}$, of a coefficient $\mathrm{n}$ reflecting the inclination of the joint and of the friction coefficient $\mathrm{r}$ :

$$
J_{f}=J_{n} /(r \cdot n)
$$

This formulation was established compiling the results of various experimental studies from the literature where the compressive strength of jointed rock samples was analysed. Different rock types and all sorts of fracture patterns were used. All those results could be described using one single formulation through the joint factor.

$$
\sigma_{c j} / \sigma_{c i}=\exp \left(-\alpha \cdot J_{f}\right)
$$

Where $\sigma_{\mathrm{cj}}$ is the jointed rock compression strength, $\sigma_{\mathrm{ci}}$ is the intact rock compression strength and $\alpha$ a positive constant number.

A negative exponential formulation can be fitted Equation (6) on the results to describe the decrease of the SRM strength with the fracture frequency:

$$
\sigma_{c r m}=113 \exp \left(-1.8 \cdot J_{F F}\right)
$$

Where 113 corresponds to the compressive strength of the intact mixture and $\mathrm{J}_{\mathrm{FF}}$ represents the the joint fracture frequency in the north-south direction. The results obtained with the SRM exhibit a qualitative match with Ramamurthy's formulation. Howerver a significant difference persists regarding the exponential constant (1.8 for the SRM and between 0.004 and 0.01 for Ramamurthy, 2001). This difference cannot be explained only by the introduction of the coefficient $n$ in the joint factor definition and requires further investigation.

\section{Conclusion}

The development of the SRM methodology has been a step forward in the rock mass characterisation process. In this particular study, the SRM has been applied to a complex environment, where dividing 
geotechnical domains with respect to their lithology is not always possible and where a strong anisotropy is induced by the embedded structures of the rock mass.

Strength anisotropy in the SRM samples could be observed. The evolution of this anisotropy with the confining pressure showed two possible trends, an increase of the anisotropy in one case and a decrease in the other. A possible explanation has been proposed for the two mechanisms involved, suggesting the ability of the SRM samples to capture different aspects of the anisotropic behaviour of a rock mass.

An attempt has been made to study the variability of rock mass properties. By modifying some input properties of the SRM sample it has been possible to study their impact on the rock mass strength. An evaluation of the rock mass strength variability has been possible and expressed as a function of the variability of the input parameters. It has resulted in the definition of confidence intervals on the rock mass strength from which information for reliability analysis can be obtained. Further analysis is however, required for a better understanding of how the joint size distribution impact the rock mass strength.

\section{Acknowledgements}

The research presented in this paper was funded by the sponsors of the Large Open Pit project and their support is acknowledged. The sponsors are Anglo American plc, Barrick Gold Corporation, BHP Billiton Innovation Pty Ltd, Corporacion Naciónal Del Cobre De Chile ('Codelco'), Compania Minera Dona Inès de Collahuasi SCM ('Collahuasi'), DeBeers Group Services (Pty) Ltd, Newcrest Mining Ltd, Newmont Australia Ltd, Xstrata Queensland Ltd, Debswana Diamond Co, the RioTinto Group, and Vale (formerly CVRD). The author is grateful to BHP Billiton for providing data from the Nickel West project for this study, and to the Itasca Consulting Group in Minneapolis for their technical and numerical contribution.

\section{References}

Hsu, S-C., and Nelson, P. (2006) Material spatial variability and slope stability for weak rock masses. Journal of Geotechnical and Geoenvironmental Engineering, 132(2), pp. 183-193.

Itasca Consulting Group, Inc. (2006) PFC3D (Particle Flow Code in 3 Dimensions). Version 3.1.

Jefferies, M., Lorig, L. and Alvarez, C. (2008) Influence of Rock-Strength Spatial Variability on Slope Stability. Proceedings First International FLAC/DEM Symposium on Numerical Modeling, Minneapolis, US.

Julius Kruttschnitt Mineral Research Centre (2000) JoinStats, Version 1.15.

Lyman, G.J. (2003) Rock fracture mean trace length estimation and confidence interval calculation using maximum likelihood methods. International Journal of Rock Mechanics and Mining Sciences, 40(6), pp. 825-832.

Mas Ivars, D., Pierce, M., DeGagnné, D. and Darcel, C. (2008) Anisotropy and scale dependency in jointed rock-mass strength - A Synthetic Rock Mass Study. Proceedings First International FLAC/DEM Symposium on Numerical Modeling, Minneapolis, USA.

Nouguier-Lehon, C., Cambou, B. and Vincens, E. (2003) Influence of particle shape and angularity on the behaviour of granular materials: a numerical analysis. International Journal for Numerical and Analytical Methods in Geomechanics, 27(14), pp. 1207-1226.

Pierce, M., Cundall, P., Potyondy, D. and Mas Ivars, D. (2007) A Synthetic Rock Mass Model for Jointed Rock. In Rock Mechanics: Meeting Society's Challenges and Demands, 1st Canada-US Rock Mechanics Symposium, Vancouver, pp. 341-349.

Potyondy, D.O. and Cundall, P.A. (2004) A Bonded-Particle Model for Rock. International Journal of Rock Rock Mechanics and Mining Science, 41(8), pp. 1329-1364.

Ramamurthy, T. (1993) Strength and modulus responses of anisotropic Rocks. In Comprehensive rock engineering, Vol. 1, Pergamon Press, pp. 313-29.

Ramamurthy, T. (2001) Shear strength response of some geological materials in triaxial compression. International Journal of Rock Mechanics and Mining Science, 38(5), pp. 683-697. 